\title{
EDITORIAL
}

\section{Existential isolation}

I took a test in Existentialism. I left all the answers blank and got 100 .

$$
\text { — Woody Allen, } 1986
$$

\section{THE ULTIMATE CONCERNS OF HUMAN EXISTENCE}

For those of us immersed in the care of advanced cancer patients in the palliative care setting, their experiences of suffering and despair are all too familiar. We hear their stories of fear, loss, sadness, anger, and guilt. We feel them grapple with suffering, burden, loneliness, meaninglessness, and even the struggle of being versus nonbeing. Sometimes patients need little encouragement from us to discuss their engagement in the experience of the existential threat of death; but often we are the ones who gently open the door inviting such discussions, out of a belief in the therapeutic nature of expressing these concerns and the associated emotions. Existential psychotherapies in the palliative care setting have their foundation in existential philosophy, and the study of human existence as a philosophical construct has informed the development of multiple existentially oriented psychotherapies in the advanced cancer setting (e.g., supportive-expressive psychotherapy, cognitive-existential psychotherapy, dignity therapy, meaning-centered psychotherapy). It was Irvin Yalom (1980) who brought existential psychotherapy into the forefront of modern psychotherapies aimed at addressing the existential concerns of human beings. Yalom is noted for his elucidation of the four basic human existential concerns, or what many refer to as "the ultimate concerns of human existence." He described these basic human concerns as follows: (1) death: the inevitability of death, the ultimate limitation; (2) freedom: the responsibility and freedom to make our lives as we will, to be the sole authors of our lives, thus leaving us groundless with no one to determine our destiny but ourselves; (3) existential isolation: our ultimate aloneness - we are born alone and die alone; and (4) meaninglessness: the concern that we will have ulti- mately led a life without meaning, the absence of a given meaning that thus leaves us solely responsible for the creation and experience of meaning in our lives.

\section{EXISTENTIAL ISOLATION}

These basic ultimate human existential concerns are the core of much of the suffering and existential despair that we all experience, particularly when we are forced to face the reality and proximity of death (as our patients with advanced cancer do). As a clinician and researcher in this sphere of human suffering and existential despair for some 15 years, I have often turned to Yalom's work and these basic human existential concerns as a framework for understanding, assessing, and treating patients in existential despair. Over the years, I have learned more and more about each of these existential concerns, enriching my understanding of them and using them in expanded ways as part of my psychotherapeutic approach. I must admit, however, that "existential isolation" was a construct I never fully understood or embraced. Its true meaning and clinical applications evaded me. In lectures on existential issues in end-of-life care, I would include existential isolation as a basic existential human concern, and without much deep understanding repeat the phrase "ultimately, we are born alone, we live alone, and we die alone."

I wasn't quite sure I even understood what that meant! Was I talking about loneliness? Isolation? Disconnection? I believe I would often move toward concepts of the importance of connectedness: connectedness to each other, to the continuum of time (past, present, future), and to something transcendent, something or some idea or value or concept greater than ourselves. I was conceptualizing "existential isolation" as relational, transpersonal, as connection, as loneliness. I would even describe connectedness, love, and transcendence as antidotes to the terror of isolation (existential isolation). Martin Buber (1958), in describing existential isolation, 
would cite the differentiation of the I-Thou relationship versus the I-It relationship. The I-Thou relationship brought one more authentic and deeper connection to another human being, but this concept was in fact likely the genesis of my tendency to see this type of connectedness with the other as an antidote to transpersonal isolation rather than existential isolation.

Yalom describes "existential isolation" as a more fundamental isolation - an isolation from every creature and every element of our perceived world. No matter how close one becomes to another (a child, a parent, a lover), there is an ultimate unbridgeable gap. No matter what our experience is of the world, it is not the same experience as anyone else's-no one else's. I once described the process of caring for my dying mother in the pages of this journal. I wrote that I accompanied her "up to the point beyond which I could no longer follow." It was a journey she ultimately had to make alone, one that only she could make. As opposed to isolation or loneliness, existential isolation is an intrapersonal experience. Existential isolation really refers to the concept that each of us is responsible for creating our own lives and living that life authentically. So, in fact, we are completely unique in every aspect of our existence and our death. Yalom (1980) writes, "To the extent that one is responsible for one's life, one is alone. Responsibility implies authorship; to be aware of one's authorship means to forsake the belief that there is another who created and guards one. Deep loneliness is inherent in the act of self-creation." There is also inherent loneliness in the realization that our world, our reality, can never be completely shared and experienced in the exact same way by another. Our reality, the people we love, our consciousness ceases to exist the moment we die. And the memory of our existence dies when the last person who remembers us dies.

\section{EXISTENTIAL UNIQUENESS}

But is this truly "isolation"? Does the act of self-creation actually produce the experience or terror of "loneliness"? I am not sure. The other day I was having a discussion with a bright 25 year old who had widely metastatic melanoma. He knew he was going to die, and we were discussing life and death and his attitude toward a variety of existential concerns, including existential isolation. In describing the concept of existential isolation, I found myself not thinking of loneliness, or of isolation, fear, or despair. I found myself thinking of the beauty of the uniqueness of each of our lives. I heard myself say to him, "It's not so much existential isolation as it is our existential uniqueness." My young patient smiled and said, "Yeah, doc, I like that. Existential uniqueness. It's cool to be unique, isn't it?" "Yeah, it's cool," I said, "but I guess it can be a lonely road to travel sometimes."

\section{REFERENCES}

Allen, W. \& Sunshine, L. (1986). The Illustrated Woody Allen Reader. New York: Knopf.

Buber, M. (1958). I and Thou, 2nd rev. ed. Trans. R.G. Smith. New York: Scribner.

Yalom, I.D. (1980). Existential Psychotherapy. New York: Basic Books.

WILLIAM BREITBART, M.D.

Editor-in-Chief, Palliative \& Supportive Care Chairman, Jimmie C. Holland Chair in Psychiatric Oncology Chief, Psychiatry Service, Department of Psychiatry \& Behavioral

Sciences

Memorial Sloan Kettering Cancer Center 641 Lexington Avenue, 7th Floor New York, New York 10022 E-Mail: Breitbaw@mskcc.org 